\title{
Protection against Infectious Bronchitis Virus, a Corona Virus Infection, Using Ostrich Antibodies
}

\author{
Yasuhiro Tsukamoto*, Yuna Nakano, Kazuhide Adachi \\ Department of Animal Hygiene, Graduate School of Environmental \& Biological Sciences, Kyoto Prefecture University, \\ Kyoto, Japan \\ Email: *ytsuka@kpu.ac.jp
}

How to cite this paper: Tsukamoto, Y., Nakano, Y. and Adachi, K. (2018) Protection against Infectious Bronchitis Virus, a Corona Virus Infection, Using Ostrich Antibodies. Health, 10, 1294-1308. https://doi.org/10.4236/health.2018.101010 $\underline{0}$

Received: September 15, 2018

Accepted: October 9, 2018

Published: October 12, 2018

Copyright $\odot 2018$ by authors and Scientific Research Publishing Inc. This work is licensed under the Creative Commons Attribution International License (CC BY 4.0).

http://creativecommons.org/licenses/by/4.0/

\begin{abstract}
In chickens, infectious bronchitis (IB) is a major respiratory disease. The respiratory system is the primary multiplication site of IB virus (IBV), a coronavirus, after which the virus is distributed to other organs. Poultry farms sustain considerable economic damage due to IB outbreaks in flocks, since IB causes a severe reduction in weight gain in chicks. In the present study, we produced the ostrich IgY against IBV by immunizing female ostriches with the IB viral antigens. The resultant purified IgY showed a strong neutralizing activity against IBV infection of cultured primary chick kidney cells. The infectivity of IBV was markedly inhibited in the trachea of chicks when ostrich IgY was injected intra-muscularly into newly hatched chicks prior to viral inhalation challenge at two weeks of age. Furthermore, the infection was strongly blocked in the tracheae when IgY was injected into chicks at one day and one week of age, with viral inhalation performed at three weeks of age. These findings suggest that the injection of ostrich IgY can help protect young chicks from IBV infections. In south Asian and African countries, broiler chicks are sent to poultry market around 30 days of age, so it is important to prevent IB outbreaks in very young flocks. We strongly believe that ostrich IgY will be a powerful weapon against IB infection in poultry farms on a wide scale and also hope that these findings will aid in the development of antibody vaccines for new type corona viruses, SARS-CoV and MERS-CoV.
\end{abstract}

\section{Keywords}

Ostrich, Antibody, Infectious Bronchitis, Corona Virus 


\section{Introduction}

Chicken is a major source of protein and one of the most common and widespread domestic animals. Broiler chickens are a gallinaceous domesticated fowl, bred and raised specifically for meat production. Most commercial broilers reach slaughter-weight between three to five weeks of age in Asian and African countries. Because the meat broilers are quite young at slaughter, their behavior and physiology are that of an immature bird. Young chickens are susceptible to several infectious diseases, including avian encephalitis, pullorum, Mareck's disease, laryngotracheitis, and infectious bronchitis (IB).

IB is one of the most important respiratory diseases in chickens. The respiratory system is the primary infection site of IB virus (IBV), after which the virus distributes to other organs [1] [2] [3]. The virus is acquired following inhalation or direct contact with contaminated poultry, litter, equipment, or other fomites. Vertical transmission of IBV within the embryo has never been reported, but the virus may be present on the shell surface of hatching eggs via shedding from the oviducts or alimentary tract. Death in chickens due to IB occurs mainly due to renal failure in the nephrotropic strain [2]-[7], although respiratory lesions are repaired almost completely within two to three weeks if the chickens survive [5] [8] [9] [10]. Reductions in egg production and quality are noted in layer and breeder chickens. The virus may replicate in the oviduct and cause permanent damage in immature females or pullets, resulting in limited egg production later in life. Infection of hens during laying may reduce egg production by $10 \%$ or more, depending on the immune status of the flock. Furthermore, egg shells are commonly malformed and more susceptible to breakage due to thinning of the shell.

While chickens of all ages are susceptible, the disease is most severe in baby chicks, causing mortality. As the chickens age, they become more resistant to the nephropathogenic effects, oviduct lesion, and mortality due to infection [4] [8] [11].

Perhaps most importantly, however: a reduction in weight gain and feed efficiency are observed in meat-type broiler chickens. In our preliminary studies, broiler chicks showed a marked reduction in their body weight gain when they were infected with IBV in the early growing days.

IBV spreads rapidly among chickens in a flock. The disease is highly contagious and has a very short incubation period. Susceptible birds placed with infected chickens usually develop typical symptoms within $24-48 \mathrm{~h}$. The virus has been isolated consistently from the trachea, lung, kidney, and bursa of chickens at $24 \mathrm{~h}$ and though the seventh day after aerosol exposure [12]. An IBV living vaccine strain may persist in various internal organs for 163 days or longer [13]. During this period, the virus may be periodically shed in nasal excretions and feces. Reports of extended and intermittent shedding are evidence of the potential risk of flock-to-flock transmission via contamination of personnel or equipment. Challenge of vaccinated birds with homologous virus results in much lower titers of recovery challenge virus and for a shorter period than in unvaccinated 
birds [14] [15] [16] [17]. When the challenged virus is of a heterogenous type, the challenged virus may replicate in high titers and cause clinical disease [18]. However, young chicks fail to obtain immunity to prevent IBV infection because of the time lag between the acquisition of immunity and viral outbreaks in flocks. Accordingly, young chicks are susceptible to IB infection and sustain growth damage. The most effective method of reducing the impact of a pandemic is suggested to be prophylaxis with a safe and effective vaccine. However, a number of commercial IB vaccines have been reported to be ineffective for preventing IB infection in young broiler chicks when heterophilic IBV strains appear in a flock.

Antibodies are being used increasingly frequently for research, diagnoses, and therapeutic purposes. However, antibodies from experimental mammals, including mice and rabbits, are not adapted for industrial usage because of their high production cost. Avian eggs have recently proven attractive as a source for the noninvasive production of antibodies with applications in research, diagnoses, and immunotherapy [19] [20]. In addition, the production of avian antibodies offers many advantages over that of mammalian antibodies with regard to antigen specificity, production cost, and usage [21]. The predominant class of immunoglobulin in birds is immunoglobulin yolk ( $\operatorname{IgY})$, which is transferred from the blood to the yolk to confer passive immunity to the embryo [22]. Although the IgY and IgG of mammals are functionally equivalent, they differ with respect to certain physicochemical properties [23].

We recently developed a convenient method for mass-producing antibodies using the female ostrich (Struthio camelus). The ostrich grows up to $250 \mathrm{~cm}$ in height and $160 \mathrm{~kg}$ in weight, and their life span is about 60 years. Ostrich eggs weight about $1.5 \mathrm{~kg}$ and are 30-fold bigger than chicken eggs. They can lay 100 eggs every year. We can purify about $4 \mathrm{~g}$ of IgY per ostrich egg, meaning about $400 \mathrm{~g}$ of IgY can be obtained from a single ostrich in the course of a year. Recent developments in breeding have permitted low-cost egg production from ostriches, as they can be fed factory waste from bean sprout production. Accordingly, we strongly believe that ostrich eggs might provide an excellent source of antibody for industrial purposes, including health care for flocks of domestic fowl [24] [25].

In the present study, we attempted to produce antibodies against IBV from ostrich eggs. The whole bodies of the IBV containing various proteins were considered suitable antigens to immunize the ostrich for the following reasons: IBV entry is mediated by the receptor-binding domain of spick protein, and the adaptation of avian viruses to humans is associated with spick protein specificity; the $\mathrm{M}$ protein is important for fusing the IBV envelope to the host cell membrane; and the E protein encourages viral shedding from most cells. Thus, the blockage of various antigens of IBV by IgY may lead to the inactivation of the viral infection of host cells. We found that a high amount of neutralizing antibody against IBV was generated by an ostrich via our simple and economical method; this approach may lead to the development of anti-viral therapy against IB outbreaks in broilers. 


\section{Materials and Methods}

\subsection{The Generation of Antibodies against IBV Antigens}

An inactivated M41 strain of IBV, a Massachusetts type strain was used as antigens for the immunization of the ostrich. The laying ostriches were immunized intra-muscularly in the lumbar region at multiple sites with IBV antigens ( $50 \mu \mathrm{g} / \mathrm{bird}$ ). Boosters were given every other week with the same antigen. The eggs were collected daily from the initial immunization day. The yolk was separated from the albumin using an egg yolk separator, and the volume of the yolk was recorded and stored at $-20^{\circ} \mathrm{C}$. Serum samples were also collected every week and stored at $-20^{\circ} \mathrm{C}$. The subsequent antibody purification was performed according to our previous study (Adachi et al., 2008). Finally, the purified antibody solutions were verified by $10 \%$ SDS-PAGE under non-reducing or reducing conditions and stained with Coomassie Brilliant Blue.

\subsection{An Enzyme-Linked Immunosorbant Assay (ELISA) Using Ostrich IgY}

Each well of a polystyrene ELISA plate (Sumitomo Bakelite, Japan) was coated with $0.2 \mu \mathrm{g}$ IBV antigen in phosphate-buffered saline (PBS), and the plate was incubated overnight at $4^{\circ} \mathrm{C}$. Each of the following incubation steps were preceded by washing the wells twice with PBS containing 0.05\% Tween 20. The wells were blocked for nonspecific binding by the addition of a commercial blocking buffer (DS Pharma Biomedical, Suita, Japan) and incubated at $37^{\circ} \mathrm{C}$ for $2 \mathrm{~h}$. The serial dilutions of purified IgY were added vertically to the wells, and the plates were incubated at $37^{\circ} \mathrm{C}$ for $1 \mathrm{~h}$. HRP-conjugated rabbit IgG against ostrich IgY diluted (1:5000) in PBS was dispensed into each well. The plate was incubated for $1 \mathrm{~h}$ at $37^{\circ} \mathrm{C}$. A substrate buffer containing TMB (Sumitomo Bakelite, Japan) was then added to each well, and the plates were incubated at $37^{\circ} \mathrm{C}$ for $15 \mathrm{~min}$. The reaction was terminated by the addition of a stopping reagent (1.25 M sulfuric acid). The absorbance was recorded at $450 \mathrm{~nm}$ using an ELISA plate reader (DS Pharma Biomedical).

\subsection{Primary Culture of Chicken Kidney (CK) Cells}

Chicks were sacrificed with pentobarbital sodium solution, and the bilateral kidneys were removed and dissolved in trypsin-EDTA solution (Nacalai Tesque, Kyoto, Japan). After centrifugation, the cells were re-suspended in DMEM (Nacalai Tesque) containing $10 \%$ fetal bovine serum and seeded into each well of 96-well microculture plates at $37^{\circ} \mathrm{C}$. At semiconfluent stages, the cells were used for viral infection or antibody titration tests.

\subsection{Viral Infectivity $\left(\mathrm{TCID}_{50}\right)$ Assays}

A nephrotrophic strain of IBV (A1 strain) was used in this study throughout (Tsukamoto et al., 1997). The viral solutions were titered using CK cells in 96 -well microtiter plates by serial 10 -fold dilutions of the samples as a routine 
procedure to observe the cytopathic effects (CPEs).

\subsection{Immunocytochemistry}

The primary CK cells seeded into the wells of the microtiter plate were infected with IBV $\left(100 \mathrm{TCID}_{50}\right)$ for $2-3$ days at $37^{\circ} \mathrm{C}$. The cultures showing CPEs were fixed with $10 \%$ buffered formalin. After being washed in PBS, the cells were incubated with FITC-conjugated ostrich IgY (1:4000) against IBV for $1 \mathrm{~h}$ at $37^{\circ} \mathrm{C}$ following a sufficient number of washes in PBS. Finally, the specific signal was observed under fluorescence microscopy.

\subsection{Neutralization Assays for IBV Infection}

For the standard neutralization assay of cell cultures, the serial dilutions of ostrich IgY were mixed at a ratio of 1:1 with IBV $\left(100 \mathrm{TCID}_{50}\right)$, incubated for $1 \mathrm{~h}$ at $37^{\circ} \mathrm{C}$, and transferred to a microtiter plate with a CK monolayer. After 2 - 3 days' incubation at $37^{\circ} \mathrm{C}$, the cultures were inspected for CPEs. The neutralizing titer, expressed as the reciprocal of the IgY dilution at which virus growth was inhibited by $50 \%\left(\mathrm{IC}_{50}\right)$, was calculated based on the number of virus-negative wells and the IgY dilution, according to a previous report [26].

\subsection{IBV Challenge to Chicks and Ostrich IgY Administration}

- Challenge 1

The chicks were intratracheally or intravenously inoculated with IBV at a dose of $10^{3.5} \mathrm{TCID}_{50}$. They were injected intra-muscularly with preimmune IgY $(2 \mathrm{mg} / \mathrm{bird})$ or IgY against IBV $\left(3 \times 10 \mathrm{IC}_{50} /\right.$ bird $)$ on the day before viral inoculation. The birds were sacrificed with pentobarbital sodium solution, and the tracheae and kidneys were removed from the chicks at four to eight days after viral challenge. The specimens were fixed in $10 \%$ neutral buffered formalin and used for histopathological and viral detection assays.

- Challenge 2

One-week-old chicks were housed in an infection box $(32 \times 22 \times 20 \mathrm{~cm})$ placed in the BSL-2 safety cabinet and inhalated with micro mists of viral solution from a medical nebulizer (OMRON, Kyoto, Japan). To confirm the chick model of IB, we put the chicks in a box and sprayed the virus with a nebulizer. By optimizing the viral volume and spray time, we were able to establish an infection model close to natural infection. The presence or absence of infection was judged by the onset of bronchitis by histopathological search or the proliferation of virus on tracheal epithelium by immunofluorescent antibody method. As a result, a total of $10^{3.5} \mathrm{TCID}_{50}$ IBV were nebulized for $30 \mathrm{~min}$. At four days post-inhalation with IBV, the tracheae were sampled from the chicks and used for histopathological analyses.

- Challenge 3

Newly hatched chicks were injected intra-muscularly with ostrich $\operatorname{IgY}(3 \times$ $\left.10 \mathrm{IC}_{50} / \mathrm{bird}\right)$ or preimmune IgY ( $\left.2 \mathrm{mg} / \mathrm{bird}\right)$. They were then exposed to IBV 
$\left(10^{3.5} \mathrm{TCID}_{50}\right)$ via inhalation in an infection box for the next week. The tracheae were sampled at four days post-viral challenge and used for histopathology and viral-immunohistochemistry.

- Challenge 4

Newly hatched chicks were injected intra-muscularly with ostrich $\operatorname{IgY}(3 \times$ $\left.10 \mathrm{IC}_{50} / \mathrm{bird}\right)$ or preimmune $\operatorname{IgY}(2 \mathrm{mg} / \mathrm{bird})$. At two weeks post-injection, they were exposed to IBV $\left(10^{3.5} \mathrm{TCID}_{50}\right)$ via inhalation in an infection box. The tracheae were then sampled at four days post-viral challenge and used for histopathology and viral-immunohistochemistry.

- Challenge 5

The chicks were injected intra-muscularly with ostrich $\operatorname{IgY}\left(3 \times 10 \quad \mathrm{IC}_{50}\right)$ or preimmune IgY $(2 \mathrm{mg})$ when newly hatched and at 1 week of age. They were exposed to IBV $\left(10^{3.5} \mathrm{TCID}_{50}\right)$ via inhalation in an infection box at three weeks of age ( 2 weeks after the final IgY injection). The tracheae were sampled at four days post-viral challenge and used for histopathology and viral-immunohistochemistry.

In the above examinations, at least five birds were used in each infection group. The experiments were approved by the animal care committee of Kyoto Prefecture University.

\subsection{Histopathology}

The tracheal and renal specimens for histopathology were fixed with neutral buffered formalin, embedded in paraffin, sectioned at $3 \mu \mathrm{m}$, and stained with hematoxylin and eosin (H\&E).

\subsection{The Detection of Viral Antigens by Immunohistochemistry}

The IBV antigens in tracheae or kidneys were detected by a direct immunofluorescent method. Frozen sections fixed with neutral buffered formalin and equivalated in $20 \%$ sucrose in PBS were incubated with fluorescein isothiocyanate (FITC)-conjugated ostrich anti-IBV antibody in a moist chamber at $37^{\circ} \mathrm{C}$ for 1 h. After being washed with PBS, the sections were mounted in glycerol and examined for their specific fluorescence under a fluorescent microscope.

\section{Results}

\subsection{Ostrich Antibodies against IBV Antigen}

The IgY from the ostrich immunized with IBV antigens was purified from the yolk and visualized by SDS-PAGE. The molecular weight of ostrich IgY is around $200 \mathrm{kDa}$ (heavy chain, $64 \mathrm{kDa}$; light chain, $28 \mathrm{kDa}$ ) and is heavier than that of rabbit IgG (data not shown). The IgY against IBV antigens was titered by an ELISA from the primary immunization day. ELISA titer was recorded as highest dilutions showing over twice absorbance of preimmune IgY. The titers increased dramatically in the yolk from two weeks after the primary immunization and peaked at one month. At the hyper-immune stage showing ELISA titer over 12,640, about $4 \mathrm{~g}$ of $\operatorname{IgY}$ could be purified from a single egg, resulting in up 
to $400 \mathrm{~g}$ of IgY against the IB virus being obtainable from a single female ostrich each year. The IgY from the eggs immunized with antigens showed high reactivity to IBV antigens.

\subsection{Neutralization Activity of Ostrich IgY to IBV Infection in Culture Cells}

IBV solution was adsorbed onto CK cells and incubated for another 2 - 3 days at $37^{\circ} \mathrm{C}$. The CK cells showed typical CPEs after IBV infection that were markedly inhibited by ostrich IgY against IBV. On immunofluorescent staining with the ostrich IgY, IBV antigens were detected in many CK cells (Figure 1). Serial dilutions of viral solution were added to the culture media. At three days post-inoculation, the wells with CPEs were counted, and the $\mathrm{TCID}_{50}$ values were scored. The stock viral solution showed an infection titer $\left(10^{3.5} \mathrm{TCID}_{50} / 25 \mu \mathrm{L}\right)$ and was used in further studies. The IBV solution at $100 \mathrm{TCID}_{50}$ was then mixed with various volumes of pre- or anti-IBV IgY and used to inoculate the culture cells. At 3 days post-inoculation, the wells with CPEs were counted, and the $50 \%$ neutralization titer of IgY was scored. The resultant $50 \%$ neutralization titer of IgY $\left(\mathrm{IC}_{50}\right)$ was $64 \mu \mathrm{g} / \mathrm{mL}$.
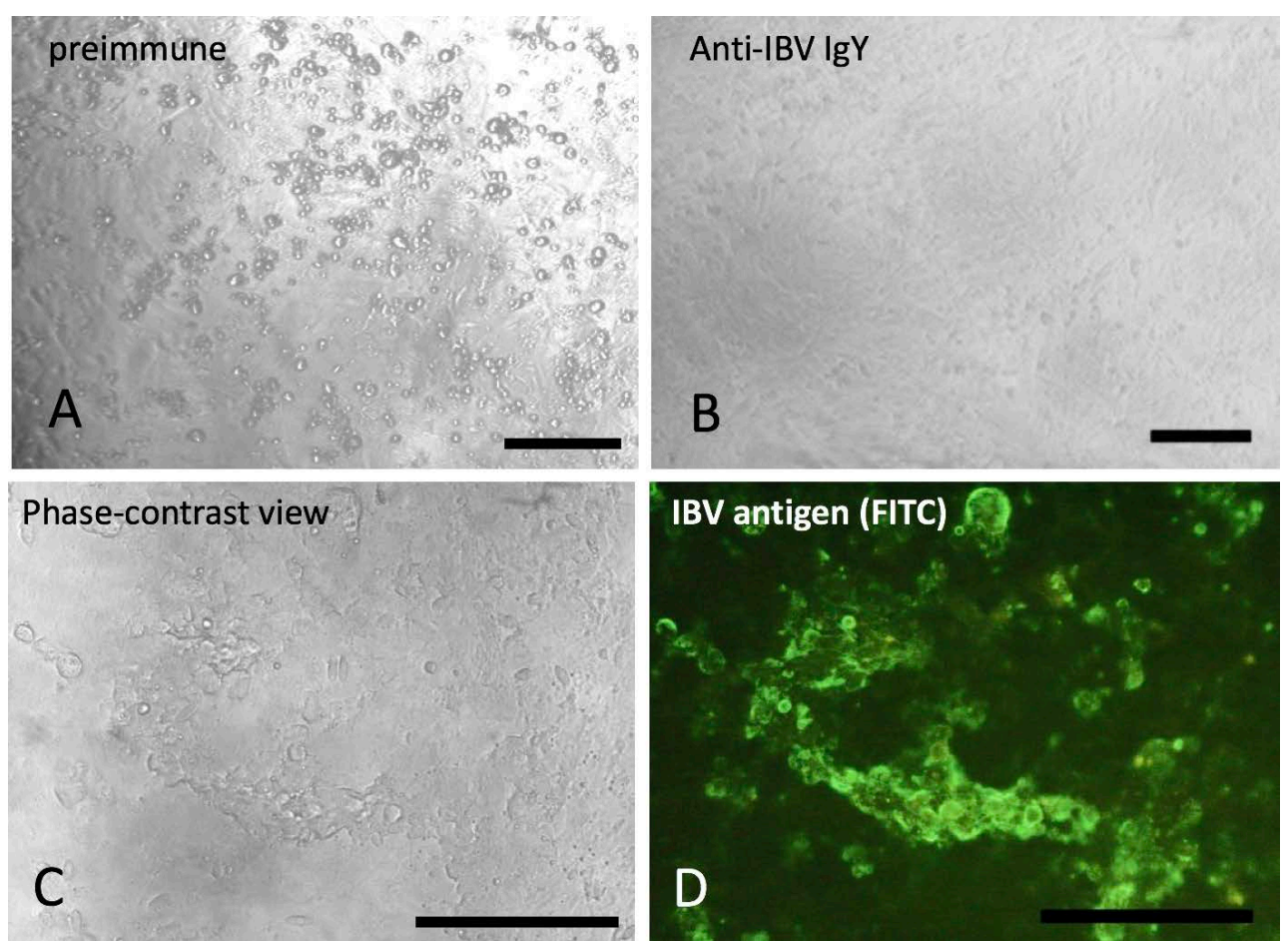

Figure 1. Infectivity of IBV to primary chick kidney cells and the neutralization activity of ostrich IgY against IBV infection. The chick kidney (CK) was dissolved with trypsin-EDTA solution and seeded onto the culture dish after sorting with a mesh. At semiconfluent stages, IBV solution was adsorbed onto the cultured CK cells and incubated for another $2-3$ days at $37^{\circ} \mathrm{C}$. The CK cells showed typical cytopathic effects (CPEs) after IBV infection (A) that were clearly inhibited with the ostrich IgY against IBV (B). On immunofluorescent staining with the ostrich IgY, IBV antigens were detected as green signals in many CK cells showing CPEs ((C), (D)). Bars, $200 \mu \mathrm{m}$. 


\subsection{Effects of Ostrich IgY on IBV Infection in Chicks}

\section{- Challenge 1}

Newly hatched chicks were intra-tracheally inoculated with IBV, and young chicks at three weeks of age were injected intravenously with IBV. The animals were injected intra-muscularly with preimmune IgY or IgY against IBV prior to viral inoculation. The tracheae and kidneys were removed from the chicks post-viral challenge and examined histopathologically and immunohistochemically (Figure 2).

In the tracheae from the IBV-inoculated chicks, the epithelial cells had degenerated to a cuboidal or flattened shape, and the basal cells had begun to proliferate. Heterophilic and lymphocytic infiltration as well as congestion and edema were observed in the submucosa. Large edematous spaces with inflammatory exudate were recognized between the degenerated epithelia and basal cells. In some areas, hyperplastic changes of epithelial cells were prominent. The surface of the lamina propria was covered by up to five to six layers of newly formed epithelial cells with no cilia; mitosis was apparent in some of these epithelial cells. In the tracheae from the infected chicks administered ostrich IgY, the mucosal surface was lined by ciliated columnar cells and goblet cells, resembling the normal tracheal tissue.

IBV-specific antigen was found in high levels in the cytoplasm of the tracheal epithelia of IB-infected chicks. In contrast, no positive reaction was found in the tracheal mucosa of the infected chicks injected with ostrich IgY prior to viral challenge. The IBV titer of tracheal swab from infected birds was almost $10^{3} \mathrm{TCID}_{50} / \mathrm{mL}$.

Furthermore, in the kidneys, interstitial nephritis was prominent in the renal medulla, with heterophilic and lymphocytic infiltration seen around the renal tubuli. IBV antigens were detected in the epithelial cells of the renal tubuli. In contrast, no pathological legions were found in the renal tissues of IgY-infected chicks prior to IB inoculation. Viral antigens were not found in whole areas of tissues.

Trachea

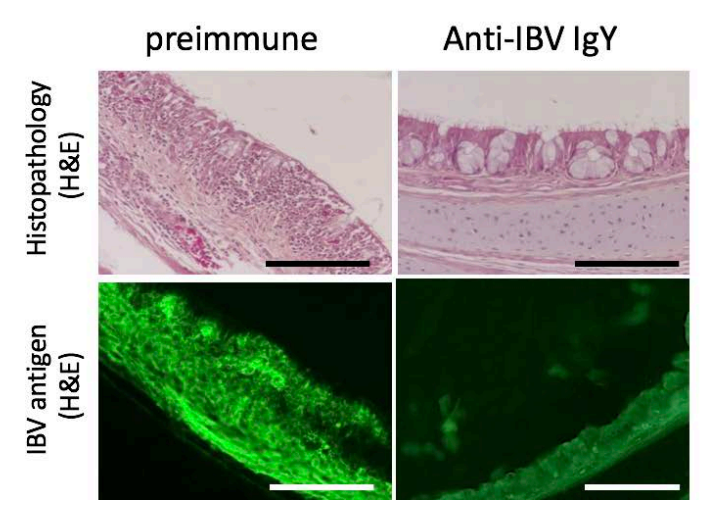

\section{Kidney}

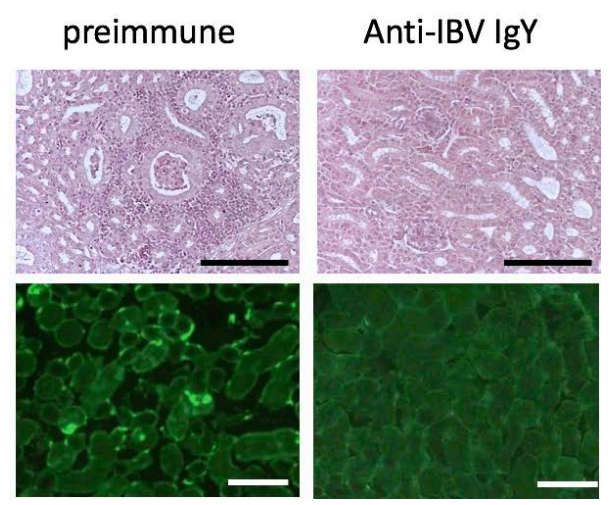

Figure 2. Effects of ostrich IgY on IBV infection in chicks via intratracheal and intravenous route. The tracheae and kidneys from infected chicks were examined histopathologically and immunohistochemically. Bars, $200 \mu \mathrm{m}$. 


\section{- Challenge 2}

The chicks were housed in a plastic box and subjected to inhalation of IBV solution using a medical nebulizer. At four days post-infection, the tracheae were examined histopathologically. Severe heterophilic and lymphocytic infiltration was found in the submucosa, and the epithelia were either degenerating or regenerating. This indicated that IBV infection model had succeeded in the tracheae via the inhalation route.

- Challenge 3

Newly hatched chicks were injected intra-muscularly with ostrich IgY or preimmune IgY one week prior to inhalation infection with IBV. Tracheal specimens were analyzed histopathologically and immunohistochemically (Figure 3). In the tracheae from IB-inoculated chicks at four days post-infection, epithelial cells showed typical inflammatory lesions of IBV infection, including the observation of heterophilic and lymphocytic infiltration, congestion, and edema in the submucosa. In the tracheae from infected chicks administered ostrich IgY, the mucosal surface was lined by ciliated columnar cells and goblet cells, resembling the normal tracheal tissue. IBV-specific antigen was found in high levels in the cytoplasm of the tracheal epithelia of IB-infected chicks. In contrast, only slight positive reaction was found in small number of epithelial cells in tracheal mucosa of the infected chicks injected with ostrich IgY prior to viral challenge.

- Challenge 4

Newly hatched chicks were injected intra-muscularly with ostrich IgY or preimmune IgY. At two weeks post-injection, they were infected with IBV via inhalation. In the tracheae infected with IBV, typical histopathological findings were found, regardless of treatment with ostrich IgY against IBV antigens. Accordingly, no inhibitory effect against the infectivity of IBV to chicks was noted with this inoculation pattern.

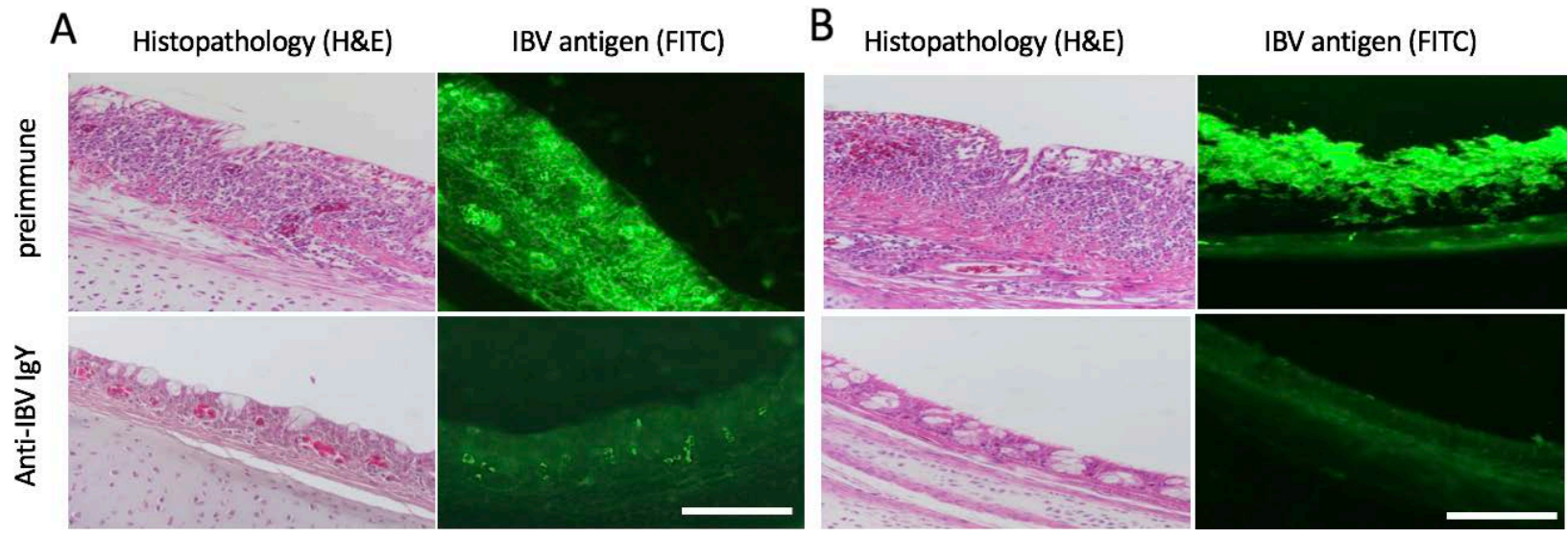

Figure 3. Effects of ostrich IgY on IBV infection in chicks via inhalation route. (A) Newly hatched chicks were injected intra-muscularly with ostrich IgY or preimmune IgY one week prior to inhalation infection with IBV. The tracheae were sampled at four days post-viral challenge. (B) The chicks were injected intra-muscularly with ostrich IgY or preimmune IgY when newly hatched and at 1 week of age. They were exposed to IBV via inhalation at three weeks of age. The tracheae were sampled at four days post-viral challenge. The tracheae from infected chicks were examined histopathologically and immunohistochemically. Bar, $200 \mu \mathrm{m}$. 


\section{- Challenge 5}

Chicks were inoculated twice with ostrich IgY: at newly-hatching and one week of age. They were then infected with IBV via inhalation two week later. Tracheal specimens were analyzed histopathologically and immunohistochemically (Figure 3 ). In the tracheae, epithelial cells showed typical inflammatory lesions of IBV infection, including the observation of heterophilic and lymphocytic infiltration, congestion, and edema in the submucosa. In the tracheae from infected chicks injected twice with IgY, the mucosal surface was lined by ciliated columnar cells and goblet cells, resembling the normal tracheal tissue. IBV-specific antigen was found in high levels in the cytoplasm of the tracheal epithelia of IB-infected chicks. In contrast, no positive reaction was found in the tracheal mucosa of the infected chicks injected with ostrich IgY only.

\section{Discussion}

Although it is established that the S1 subunit of the S protein of IBV induces VN and HI antibodies and protective immunity [27] [28] [29] [30], the mechanism underlying the protection against clinical disease remains unclear. Local respiratory tissue immunity is important for ensuring protection against IB. However, the role of local antibodies, including IgA, in preventing such infections is unclear. Some studies have reported that neutralizing antibodies in nasal secretions play a role in preventing IB and that the Harderian gland contributes to local immunity [31] [32]. The protective role of antibodies is also evident from the fact that chickens immunocompromised by IBDV infection suffer more severe episodes of IBV infection than their immunocompetent counterparts [33] [34]. Interestingly, IBV antibody was detected in the tears of vaccinated chickens [35]. However, the antibody levels in tears were not accurate indicators of IBV immunity, as determined by respiratory challenge with IBV. Antibodies therefore do not appear to be the only source of resistance, as demonstrated in chickens treated with cyclophosphamide or bursectomized in ovo and then exposed to IBV [36] [37].

Maternal-derived antibodies can reduce both the severity of the vaccinal reaction and the efficacy of the vaccine if the vaccine is of the same type used in the breeder flock immunization [38] [39]. Nevertheless, vaccination of already-maternally immune one-day-old commercial chicks is still routinely performed. In one study, maternal-derived antibody provided protection against challenge at one day and one week but not at two weeks of age [40], whereas in another study, maternal-derived antibody did not reduce the titer of re-isolation of virus infected at two days of age [41]. It has been shown that chicks hatched with high levels of maternal-derived antibody had excellent protection against challenge at one day of age but not at seven days of age. This protection significantly correlates with the levels of local respiratory antibody and not with the serum antibody levels. A high percentage of both maternal-derived antibody-positive and antibody-negative chickens failed to produce IBV antibody 
when vaccinated at one day of age by the intraocular route. In addition, maternal-derived antibody-positive chickens showed a weaker virus-neutralizing antibody response to a second IBV vaccination than antibody-negative birds. Maternal-derived antibody positive chicks experienced a more rapid decline in maternal-derived antibody after vaccination at one day of age than their unvaccinated counterparts.

In the present study, large-scale and economical antibodies against IBV were generated using a female ostrich. Neutralizing antibody has been reported to provide effective primary protection against pathogens [25] [42]. In addition, the prophylactic and therapeutic efficacy of human monoclonal antibodies against avian flu infection was also elucidated [43].

One particularly interesting and potentially important finding in the present study was the observation that the chicks were protected against IBV infection by intra-muscular injection with IBV-immunized IgY. This finding supports the application of ostrich IgY as a prophylactic treatment against IB outbreak. In the present study, a large amount of neutralization antibodies against IBV were produced cost-effectively, underscoring the potential utility of ostrich-derived antibodies for industrial purposes, including the development of anti-viral materials.

We established an inhalation model of infecting chicks with IBV, as IB occurs naturally in flocks via inhalation from other infected birds on a poultry farm. The chicks developed severe tracheitis after in-box inhalation of nebulized IBV. The infectivity of IBV was clearly inhibited in the tracheae of chicks when ostrich IgY was injected intra-muscularly prior to viral inhalation challenge at one week of age. Furthermore, the infection was completely blocked in tracheae when IgY was injected at one day and two weeks of age with viral inhalation performed at three weeks of age. Histopathologically, epithelial degeneration and inflammation were clearly ameliorated in the tracheae of chicks administered ostrich IgY prior to viral challenge. Viral replication was also inhibited in these chicks. These findings suggest that the injection of ostrich IgY can help protect young chicks from IBV infections. In south Asian and African countries, broiler chicks are sent to poultry market around 30 days of age, so it is important to prevent IB outbreaks in very young flocks. We are planning to inoculate the chicks at the poultry farms with ostrich antibodies and to examine the suppression effect of ostrich antibodies on natural infection of IBV. We strongly believe that ostrich IgY will be a powerful weapon against IB infection in poultry farms on a wide scale.

\section{Acknowledgements}

We thank Mrs. Hatsuki Matsunaga at Kyoto Prefecture University for her technical support.

\section{Conflicts of Interest}

The authors declare that there is no conflict of interest that could be perceived as 
prejudicing the impartiality of the research reported.

\section{Funding}

This study was supported in part by an innovation grant from the Japan Science and Technology Agency (JST; No. 1804).

\section{References}

[1] Bacon, L.D., Hunter, D.B., Zhang, H.M., Brand, K. and Etches, R. (2004) Retrospective Evidence That the MHC (B Haplotype) of Chickens Influences Genetic Resistance to Attenuated Infectious Bronchitis Vaccine Strains in Chickens. Avian Pathology, 33, 605-609. https://doi.org/10.1080/03079450400013147

[2] Tsukamoto, Y., Kotani, T., Shiraishi, Y., Kawamura, H. and Sakuma, S. (1996) Epithelial Cell Proliferation of Collecting Ducts and Ureters in the Regenerating Process of Interstitial Nephritis Caused by Infectious Bronchitis Virus. Avian Pathology, 25, 95-102. https://doi.org/10.1080/03079459608419123

[3] Tsukamoto, Y., Taira, E., Kotani, T., Yamate, J., Wada, S., Takaha, N., Miki, N. and Sakuma, S. (1996) Involvement of Gicerin, a Cell Adhesion Molecule, in Tracheal Development and Regeneration. Cell Growth \& Differentiation, 7, 1761-1767.

[4] Albassam, M.A., Winterfield, R.W. and Thacker, H.L. (1986) Comparison of the Nephropathogenicity of Four Strains of Infectious Bronchitis Virus. Avian Diseases, 30, 468-476. https://doi.org/10.2307/1590408

[5] Cavanagh, D., Ellis, M.M. and Cook, J.K.A. (1997) Relationship between Variation in the S1 Spike Protein of Infectious Bronchitis Virus and the Extent of Cross-Protection. Avian Pathology, 26, 63-74. https://doi.org/10.1080/03079459708419194

[6] Tsukamoto, Y., Matsumoto, T., Kotani, T., Taira, E., Takaha, N., Miki, N., Yamate, J. and Sakuma, S. (1997) The Expression of Gicerin, a Cell Adhesion Molecule, in Regenerating Process of Collecting Ducts and Ureters of the Chicken Kidney after the Nephrotrophic Strain of Infectious Bronchitis Virus Infection. Avian Pathology, 26, 245-255. https://doi.org/10.1080/03079459708419209

[7] Cavanagh, D., Mawditt, K., Britton, P. and Naylor, C.J. (1999) Longitudinal Field Studies of Infectious Bronchitis Virus and Avian Pneumovirus in Broilers Using Type-Specific Polymerase Chain Reactions. Avian Pathology, 28, 593-605. https://doi.org/10.1080/03079459994399

[8] Ambali, A.G. and Jones, R.C. (1990) Early Pathogenesis in Chicks with an Enterotropic Strain of Infectious Bronchitis Virus. Avian Diseases, 34, 809-817. https://doi.org/10.2307/1591367

[9] Bumstead, N., Huggins, M.B. and Cook, J.K.A. (1989) Genetic Differences in Susceptibility to a Mixture of Avian Infectious Bronchitis Virus and Escherichia coli. British Poultry Science, 30,39-48. https://doi.org/10.1080/00071668908417123

[10] Casais, R., Davies, M., Cavanagh, D. and Britton, P. (2005) Gene 5 of the Avian Coronavirus Infectious Bronchitis Virus Is Not Essential for Replication. Journal of Virology, 79, 8065-8078. https://doi.org/10.1128/JVI.79.13.8065-8078.2005

[11] Smith, H.W., Cook, J.K.A. and Parsell, Z.E. (1985) The Experimental Infection of Chickens with Mixtures of Infectious Bronchitis Virus and Escherichia coli. Journal of General Virology, 66, 777-786.

[12] Hofstad, M.S. and Yoder Jr., H.W. (1996) Avian Infectious Bronchitis: Virus Distribution in Tissues of Chicks. Avian Diseases, 10, 230-239. 
https://doi.org/10.2307/1588355

[13] Gay, K. (2000) Infectious Bronchitis Virus Detection and Persistence in Experimentally Infected Chickens. M.Sc. Thesis, Cornell University, New York.

[14] Cook, J.K.A., Smith, H.W. and Huggins, M.B. (1986) Infectious Bronchitis Immunity: Its Study in Chickens Experimentally Infected with Mixtures of Infectious Bronchitis Virus and Escherichia coli. Journal of General Virology, 67, 1427-1434. https://doi.org/10.1099/0022-1317-67-7-1427

[15] De Wit, J.J., de Jong, M.C., Pijpers, A. and Verheijden, J.H.M. (1998) Transmission of Infectious Bronchitis Virus within Vaccinated and Unvaccinated Groups of Chickens. Avian Pathology, 27, 464-471. https://doi.org/10.1080/03079459808419370

[16] Lambrechts, C., Pensaert, M. and Ducatelle, R. (1993) Challenge Wxperiments to Evaluate Cross-Protection Induced at the Trachea and Kidney Level by Vaccine Strains and Belgian Nephropathogenic Isolates of Avian Infectious Bronchitis Virus. Avian Pathology, 22, 577-590. https://doi.org/10.1080/03079459308418945

[17] Pensaert, M. and Lambrechts, C. (1994) Vaccination of Chickens against a Belgian Nephropathogenic Strain of Infectious Bronchitis Virus B1648 Using Attenuated Homologous and Heterologous Strains. Avian Pathology, 23, 631-641. https://doi.org/10.1080/03079459408419033

[18] Hodgson, T., Casais, R., Dove, B., Britton, P. and Cavanagh, D. (2004) Recombinant Infectious Bronchitis Coronavirus Beaudette with the Spike Protein Gene of the Pathogenic M41 Strain Remains Attenuated but Induces Protective Immunity. Journal of Virology, 78, 13804-13811. https://doi.org/10.1128/JVI.78.24.13804-13811.2004

[19] Gross, M. and Speck, J. (1996) Avian Yolk Antibodies in Diagnosis and Research. Deutsche tierarztliche Wochenschrift, 103, 417-422.

[20] Schade, R., Pfister, C., Halatsch, R. and Henklein, P. (1991) Polyclonal IgY Antibodies from Chicken Egg Yolk. An Alternative to the Production of Mammalian IgG Type Antibodies in Rabbits. ATLA, 19, 403-419.

[21] Schade, R., Schniering, A. and Hlinak, A. (1992) Polyclonal Avian Antibodies Extracted from Egg Yolk as an Alternative to the Production of Antibodies in Mammals-A Review. ALTEX, 9, 43-56.

[22] Larsson, A., Balow, R.M., Lindahl, T.L. and Forsberg, P.O. (1993) Chicken Antibodies: Taking Advantage of Evolution-A Review. Poultry Science, 72, 1807-1812. https://doi.org/10.3382/ps.0721807

[23] Leslie, G.A. and Clem, L.W. (1969) Phylogeny of Immunoglobulin Structure and Function. III. Immunoglobulins of the Chicken. The Journal of Experimental Medicine, 130, 1337-1352. https://doi.org/10.1084/jem.130.6.1337

[24] Adachi, K., Hagimori, K., Kikuta, T. and Tsukamoto, Y. (2008) Involvement of SC1, a Cell Adhesion Molecule, in the Progression of Mammary Gland Tumors. Molecular Medicine Reports, 1, 219-224.

[25] Adachi, K., Takama, K., Ozaki, M., Fukuda, K., Endo, I., Yamamoto, R. and Tsukamoto, Y. (2008) Inhibition of H5N1 Avian Influenza Virus Infection by Ostrich Antibodies. Molecular Medicine Reports, 1, 2003-2009.

[26] Reed, L.J. and Muench, H. (1938) A Simple Method of Estimating Fifty Percent Endo-Points. American Journal of Hygiene, 27, 493-797.

[27] Ignjatovic, J. and Galli, L. (1994) The S1 Glycoprotein but Not the N or M Proteins of Avian Infectious Bronchitis Virus Induces Protection in Vaccinated Chickens. 
Archives of Virology, 138, 117-134. https://doi.org/10.1007/BF01310043

[28] Johnson, M.A., Pooley, C., Ignjatovic, J. and Tyack, S.G. (2003) A Recombinant Fowl Adenovirus Expressing the S1 Gene of Infectious Bronchitis Virus Protects against Challenge with Infectious Bronchitis Virus. Vaccine, 21, 2730-2736. https://doi.org/10.1016/S0264-410X(03)00227-5

[29] Macnaughton, M.R., Hasony, H.J., Madge, M.H. and Reed, S.E. (1981) Antibody to Virus Components in Volunteers Experimentally Infected with Human Coronavirus 229E Group Viruses. Infection and Immunity, 31, 845-849.

[30] Song, C.S., Lee, T.J., Lee, C.W., Sung, H.W., Kim, J.H., Mo, I.P., Izumiya, Y., Jang, H.K. and Mikami, T. (1998) Induction of Protective Immunity in Chickens Vaccinated with Infectious Bronchitis Virus S1 Glycoprotein Expressed by a Recombinant Baculovirus. Journal of General Virology, 79, 719-723.

https://doi.org/10.1099/0022-1317-79-4-719

[31] Holmes, H.C. (1973) Neutralizing Antibody in Nasal Secretions of Chickens Following Administration of Avian Infectious Bronchitis Virus. Arch Gesamte Virusforsch, 43, 235-241. https://doi.org/10.1007/BF01250418

[32] Davelaar, F.G. and Kouwenhoven, B. (1976) Changes in the Harderian Gland of the Chicken Following Conjunctival and Intranasal Infection with Infectious Bronchitis Virus in One- and 20-Day Old Chickens. Avian Pathology, 5, 39-50. https://doi.org/10.1080/03079457608418168

[33] Rosenberger, J.K. and Gelb Jr., J. (1987) Response of Several Avian Respiratory Viruses as Affected by Infectious Bursal Disease Virus. Avian Diseases, 22, 95-105. https://doi.org/10.2307/1589512

[34] Thompson, B.G., Mohammed, H., Bauman, B. and Naqi, S. (1997) Systemic and Local Antibody Responses to Infectious Bronchitis Virus in Infectious Bursal Disease Inoculated and Control Chickens. Avian Diseases, 41, 519-527. https://doi.org/10.2307/1592140

[35] Gelb, J., Nix, W.A. and Gellman, S.D. (1998) Infectious Bronchitis Virus Antibodies in Tears and Their Relationship to Immunity. Avian Diseases, 42, 364-374. https://doi.org/10.2307/1592487

[36] Chubb, R.C. (1974) The Effect of the Suppression of Circulating Antibody on Resistance to the Australian Avian Infectious Bronchitis Virus. Research in Veterinary Science, 17, 169-173.

[37] Cook, J.K.A., Davidson, T.F., Huggins, M.B. and McLaughlan, P.I. (1991) Effect of in Ovo Bursectomy on the Course of an Infectious Bronchitis Virus Infection in Line C White Leghorn Chickens. Archives of Virology, 118, 225-234. https://doi.org/10.1007/BF01314032

[38] Klieve, A.V. and Cumming, R.B. (1988) Immunity and Cross-Protection to Nephritis Produced by Australian Infectious Bronchitis Viruses Used as Vaccines. Avian Pathology, 17, 829-839. https://doi.org/10.1080/03079458808436505

[39] Klieve, A.V. and Cumming, R.B. (1988) Infectious Bronchitis: Safety and Protection in Chickens with Maternal Antibody. Australian Veterinary Journal, 65, 396-397. https://doi.org/10.1111/j.1751-0813.1988.tb14283.x

[40] Mockett, A.P.A., Cook, J.K.A. and Huggins, M.B. (1987) Maternally-Derived Antibody to Infectious Bronchitis Virus: Its Detection in Chick Trachea and Serum and Its Role in Protection. Avian Pathology, 16, 407-416. https://doi.org/10.1080/03079458708436391

[41] Yachida, S., Sugimori, G., Aoyama, S., Takahashi, N., Iritani, Y. and Katagiri, K. (1981) Effectiveness of Maternal Antibody against Challenge with Infectious Bron- 
chitis Viruses. Avian Diseases, 25, 736-741. https://doi.org/10.2307/1590005

[42] Suarez, D.L. and Schultz-Cherry, S. (2000) Immunology of Avian Influenza Virus: A Review. Developmental \& Comparative Immunology, 24, 269-283.

https://doi.org/10.1016/S0145-305X(99)00078-6

[43] Simmons, C.P., Bernasconi, N.L., Suguitan, J.A.L., Mills, K., Ward, J.M., Chau, N.V.V., Tinh, T., Hien, T.T., Sallusto, F., Ha, D.Q., Farrar, J., de-Jong, M.D., Lanzavecchia, A. and Subbarao, K. (2007) Prophylactic and Therapeutic Efficacy of Human Monoclonal Antibodies against H5N1 Influenza. PLoS Medicine, 4, 928-936. https://doi.org/10.1371/journal.pmed.0040178 